\title{
Are large-scale flow experiments informing the science and management of freshwater
} ecosystems?

Julian D Olden ${ }^{1 *}$, Christopher P Konrad ${ }^{2}$, Theodore S Melis ${ }^{3}$, Mark J Kennard ${ }^{4}$, Mary C Freeman ${ }^{5}$, Meryl C Mims ${ }^{1}$, Erin N Bray ${ }^{6}$, Keith B Gido ${ }^{7}$, Nina P Hemphill ${ }^{8}$, David A Lytle, Laura E McMullen ${ }^{10}$, Mark Pyron ${ }^{11}$, Christopher T Robinson ${ }^{12}$, John C Schmidt ${ }^{13}$, and John G Williams ${ }^{1}$

Greater scientific knowledge, changing societal values, and legislative mandates have emphasized the importance of implementing large-scale flow experiments (FEs) downstream of dams. We provide the first global assessment of FEs to evaluate their success in advancing science and informing management decisions. Systematic review of 113 FEs across 20 countries revealed that clear articulation of experimental objectives, while not universally practiced, was crucial for achieving management outcomes and changing dam-operating policies. Furthermore, changes to dam operations were three times less likely when FEs were conducted primarily for scientific purposes. Despite the recognized importance of riverine flow regimes, four-fifths of FEs involved only discrete flow events. Over three-quarters of FEs documented both abiotic and biotic outcomes, but only one-third examined multiple taxonomic responses, thus limiting how FE results can inform holistic dam management. Future FEs will present new opportunities to advance scientifically credible water policies.

Front Ecol Environ 2014; 12(3): 176-185, doi:10.1890/130076 (published online 11 Feb 2014)

$\mathbf{R}^{\mathrm{i}}$ ivers provide numerous ecosystem services, including a source of water for domestic, industrial, and agricultural purposes; a means of power generation and waste disposal; routes for navigation; and sites for recreation and spiritual activities (Gleick 2003). Human regulation of river flows is now ubiquitous around the globe (Lehner et al. 2011), and further dam construction is viewed as a promising strategy to alleviate energy and water challenges associated with climate change and human popu-

\section{In a nutshell:}

- We present the first global review of documented outcomes from large-scale flow experiments (FEs) to evaluate their success in advancing freshwater science and management

- The efficiency and value of FEs can be improved by targeting critical knowledge gaps (eg integrated long-term monitoring of biotic-abiotic responses and societal perceptions) and emerging opportunities (eg defining explicit management-based objectives)

- The geographical, sociopolitical, and ecological context in which future FEs are conducted must be diversified, and related efforts must not be limited to pursuing scientific discovery alone

\footnotetext{
${ }^{1}$ School of Aquatic and Fishery Sciences, University of Washington, Seattle, WA* (olden@uw.edu); ${ }^{2}$ Washington Water Science Center, US Geological Survey, Tacoma, WA; ${ }^{3}$ Southwest Biological Science Center, US Geological Survey, Flagstaff, AZ; ${ }^{4}$ National Environmental Research Program Northern Australia Hub and Australian Rivers Institute, Griffith University, Nathan, Australia; ${ }^{5}$ Patuxent Wildlife Research Center, US Geological Survey, Athens, GA; continued on p185
}

lation growth (Poff et al. 2003; Palmer et al. 2008; Finer and Jenkins 2012). Policy makers face mounting pressure to guarantee the future sustainability of water resources while simultaneously minimizing societal and environmental costs of their actions.

Traditional dam management often dampens or eliminates natural streamflow variability over annual to decadal timescales (Haeuber and Michener 1998), shifting the timing of what seasonal variability remains and increasing daily flow variation when hydroelectric objectives are combined with water storage. However, the associated loss of natural streamflow regimes also degrades valuable ecosystem services and threatens freshwater biodiversity (Bunn and Arthington 2002; Richter et al. 2003; Naiman and Dudgeon 2011). Remediating the hydrologic effects of dams is often costly or difficult to implement, yet scientific knowledge, changing societal values, and federal mandates have required dam operations to be modified in an attempt to mitigate adverse environmental impacts on downstream ecosystems (Richter and Thomas 2007; Olden and Naiman 2010; Watts et al. 2011; Kiernan et al. 2012; Konrad et al. 2012). Scientists continue to support an experimental approach to evaluate and develop dam operations that create a more rational basis for water-management decisions and to advance broader scientific knowledge (Souchon et al. 2008; Konrad et al. 2011).

Large-scale flow experiments (FEs) have entered the mainstream of water-resource management over the past decade and the public profile of scientists and managers seeking ways to promote ecological sustainability using systematic adaptive management (Kingsford et al. 2011) is much higher than ever before. Managing water 
resources for ecological outcomes is contentious (eg Cook 2013). Such actions are expensive and potentially forego other benefits; it is therefore reasonable to test and evaluate these management actions through FEs (Figure 1). For example, in the US, the four large controlled floods from Glen Canyon Dam to the Colorado River (between 1996-2012) and the deliberate spills at four Columbia River dams (McNary, John Day, Dalles, Bonneville) to allow fish passage (in 2005) were estimated to cost \$12 million and \$57-81 million in foregone or replaced power revenue, respectively. Similarly, multi-year flow releases from the San Joaquin River's Friant Dam to benefit Chinook salmon (Oncorhynchus tshawytscha) cost water users approximately $\$ 8$ million annually in environmental fees, and the Low Summer Steady Flow experiment downstream of Glen Canyon Dam was estimated to result in approximately $\$ 25$ million in replacement energy costs. In all of these cases, the measure of success depended on one's position, perspective, and interests (eg Schmidt et al. 1998; Bradford et al. 2011; Robinson 2012). Given their monetary costs and uncertain ecological (and economic) benefits, FEs warrant thorough evaluation individually and collectively to enhance

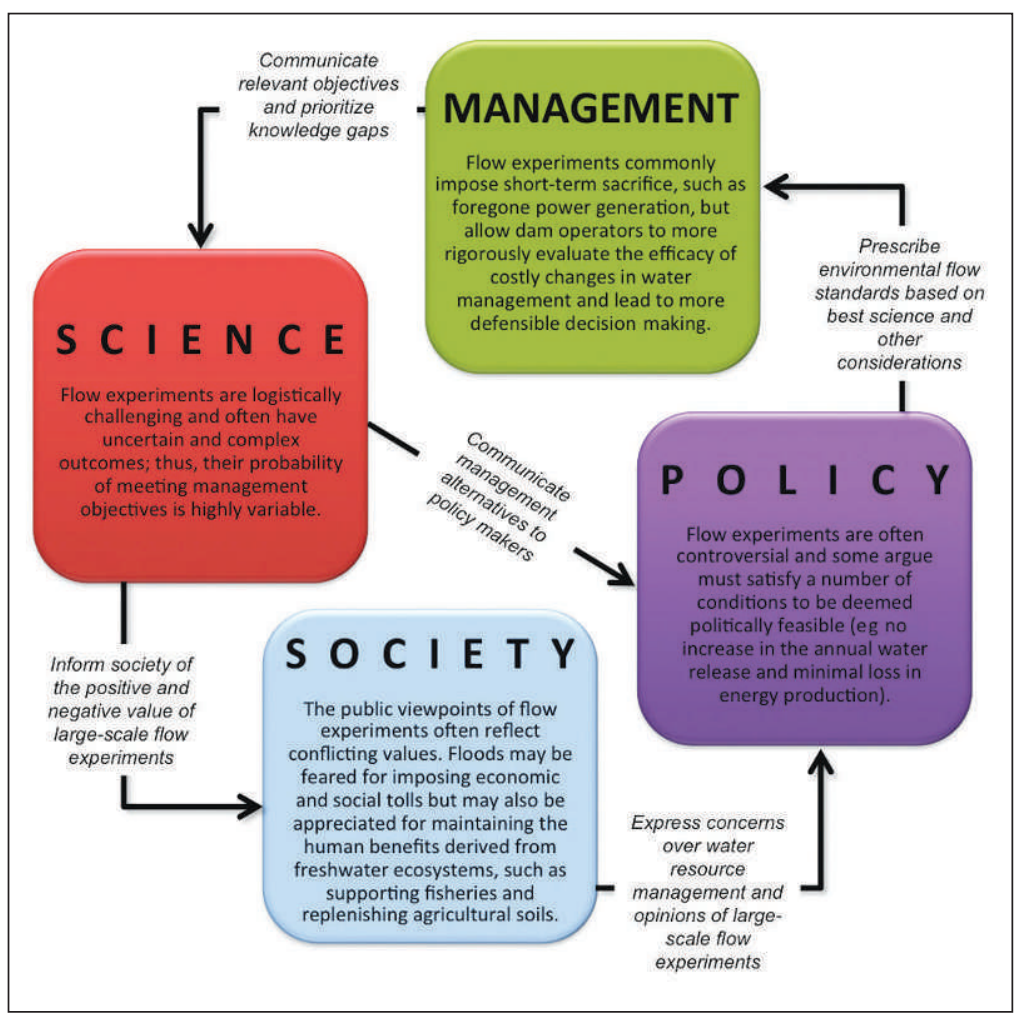

Figure 1. Flow experiments (FEs) can often be contentious within the realms of science, management, policy, and society (boxes) but are tightly interconnected (arrows) and must work in concert to maximize their potential benefits. broader scientific understanding that will increase their overall benefit to society (Acreman et al. 2000).

We present the first global review of documented outcomes from large-scale FEs to evaluate the performance of alternative dam operations on rivers, floodplains, and estuaries. Our objective is to initiate an evidence-based framework so that large-scale FEs may better inform future management efforts and policy decisions. To that end, we ask three fundamental questions:

(1) Why are large-scale FEs conducted and to what degree do they affect management objectives and practices?

(2) Are FEs advancing our scientific understanding and ability to inform future management and policy?

(3) What are the major challenges and emerging opportunities when considering future FEs to benefit water resource management?

Our assessment also highlights knowledge gaps and research needs relevant to advancing ecologically sustainable water management.

\section{A systematic review of large-scale FEs}

We systematically reviewed large-scale FEs worldwide. Conducting this review allowed us to test key hypotheses by following a strict protocol to maximize transparency and repeatability while minimizing bias (Pullin and

Stewart 2006). Below we describe the review's components, including protocol formation and search strategy, data inclusion and extraction, and data analysis.

\section{Protocol formation and search strategy}

We broadly defined a large-scale FE as field observations and analysis used to test hypotheses about physical and biological responses to a deliberate manipulation of streamflow for ecological purposes (Konrad et al. 2011). Most FEs are performed over a defined period, with distinct streamflow characteristics (the treatment policy) and focused monitoring of abiotic and biotic responses. Generally, the experimental period encompasses a discrete event, such as a high-flow pulse (Wilcock et al. 1996), reduced or seasonally varied flow (Ralston 2011), reservoir drawdown (Moore et al. 2010), non-native fish suppression flows (Korman et al. 2012), or other specified flows, although experiments can span longer-term changes in dam operations that increase minimum flow (Bednarek and Hart 2005), reduce diurnal flow fluctuations (Patterson and Smokorowski 2011), or restore flow to bypassed reaches (Bradford et al. 2011). We used Thomson ISI's Web of Science, Science Direct, JSTOR, Digital Dissertations, and relevant gray literature sources (identified through Google Scholar) to generate a database of publications through 2011 that documented large-scale FEs. We used the search terms "flow", "experiment*", and "dam*", as well as the collective knowledge 
of the current authors who represented a broad range of scientific expertise in academia and water resource management from multiple geographic regions around the world.

\section{Data inclusion and extraction}

Our search screened references to include those consistent with our definition of an FE that examined ecological outcomes (Konrad et al. 2011); we recognize that investigations of natural flow events and investigations not intended for ecological outcomes can both provide useful information for managing water resources (eg McMullen and Lytle 2012), but they do not directly address how dam operations influence complex aquatic ecosystems. For each FE we recorded:

(1) Site attributes (eg dam height, dam release structure, reservoir area) and experiment attributes, including the primary motivation (eg recovery of threatened and endangered species, regulatory or statutory requirement, scientific knowledge).

(2) The type(s) of flow manipulation (eg high-flow pulse, minimum annual flow, seasonal variability).

(3) Type(s) of biotic responses (eg major taxonomic group) and abiotic responses (eg floodplain stage, sediment size, water temperature) assessed.

(4) Details of experimental design (eg frequency of flow treatments, type of experimental control, duration of post-FE monitoring).

In addition, we assessed management outcomes in two ways. First, we considered FEs to have a clearly articulated objective if the experiment was accompanied by an explicit statement of expectations and/or a set of hypotheses that included a measurable change - even if only qualitative (increase or decrease) - in a biophysical condition other than streamflow. We relied on documentation of outcomes and the authors' assessments of whether objectives were achieved rather than applying our own independent judgment. Second, we identified a management change resulting from an FE as either a revised dam operation (ie modified water release schedule) or continued experimentation (ie additional FEs). We allowed planned future actions to qualify as a management change, given the recent implementation of most FEs. However, recommendations for future releases did not qualify as management changes. Undocumented objectives, results, or management changes may have been present in some cases but are beyond the scope of this review. See WebPanel 1 for full details on the FE attributes.

\section{Data analysis}

We tallied counts and calculated frequency statistics (representing all reported percentages) to summarize the prevalence of a subset of experimental attributes to address our specific study objectives. Additionally, odds ratios were calculated by excluding the "uncertain" response category. In some instances, multiple categories were assigned to a FE (eg for the variables "motivation for FE", "biotic outcomes measured"); multiple assignments were treated as separate data points. We purposely focused the analysis on a subset of FE attributes, both individually and in combination. Additional data summaries are presented in WebTable 1 .

\section{Global patterns in large-scale FEs}

Large-scale FEs have been used globally to evaluate the effects of alternative operations of water management facilities on rivers, lakes, floodplains, and estuaries (Figure 2). Our systematic literature review revealed 113 FEs, representing 102 dams and 98 river systems across 20 countries (see WebTable 2 for river systems and WebReferences for associated references). Generally, FE locations broadly correspond to global occurrence of large dams; several countries with numerous dams are also characterized by the largest number of FEs (Figure 2). For example, FEs are more common in the US $(n=56$ locations), Australia ( $n=15$ locations), and South Africa ( $n=$ 4 locations) - countries representing the origins of many of the original flow protection methodologies and now considered leaders in progressive water policy (Arthington 2012). Exceptions to the geographic pattern include China, Japan, India, Norway, Spain, France, and Brazil, where, despite the presence of numerous large dams, there is relatively little published evidence for past FEs. Since the first documented FE in 1965 involving high pulse flows from Glen Canyon Dam, such operations have become more commonplace and have been predominantly implemented by facilities operated for power generation, water supply, and flood control (Figure 2).

The geographical, sociopolitical, and managerial context in which FEs are conducted must be diversified by focusing future efforts in data-deficient regions such as Southeast Asia, northern and western Europe, and South America. Because many of these underrepresented regions are also where the greatest numbers of large dams are planned or are currently being constructed (eg Finer and Jenkins 2012), the need for FEs is critical in helping to inform operation strategies and related policies. FEs have also involved relatively tall dams (mean height $=65 \mathrm{~m}$, range $=5-216 \mathrm{~m})$ as compared with the world's large dams (mean height $=46 \mathrm{~m}$, range $=2-335 \mathrm{~m}$; Lehner et al. 2011). This suggests that knowledge derived from past FEs is biased toward large dams, since $>90 \%$ of experiments were conducted below dams $>15 \mathrm{~m}$ in height; more than half of these are considered megadams, exceeding $50 \mathrm{~m}$ in height (WebFigure 1). This bias likely results from the greater perceived impact of large dams and the potential political incentives to undertake large-scale adaptive management initiatives. Large dams 


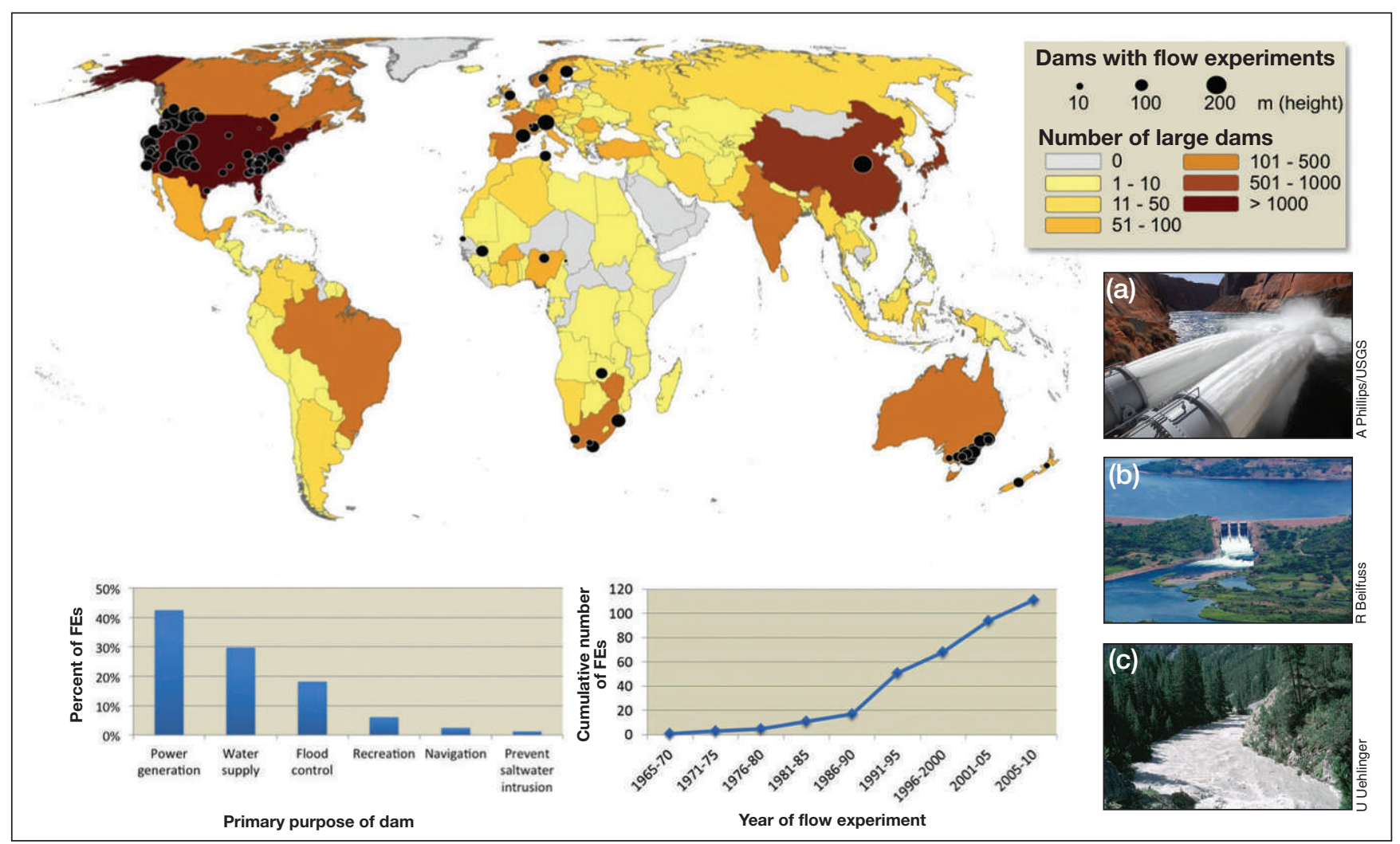

Figure 2. Large-scale FEs ( $\mathrm{n}=113$ ) have involved 102 dams globally to evaluate water management actions on river $(83 \%$ of experiments), floodplain (10\%), estuary (5\%), and lake (2\%) ecosystems. Country-level shading represents the number of large dams according to the Global Reservoir and Dam database (Lehner et al. 2011). Inset charts display the primary purpose of the dam (lower left) and cumulative number of FEs over time, based on the first year of investigation (lower right). River systems and dams are listed in WebTable 1. Photographs depict the experimental floods from (a) Glen Canyon Dam, Colorado River; (b) Itezhi-tezhi Dam, Kafue River; and the (c) River Spöl downstream from the dam at Punt dal Gall.

may also present better opportunities for conducting FEs because of greater reservoir storage capacity and greater control over releases when compared with those of small dams. The relevancy of FEs for mitigating the impacts of small dams is uncertain given that the ecological impacts of these structures are more related to habitat fragmentation than to hydrologic alteration.

\section{Why are large-scale FEs conducted and were management objectives achieved and management practices changed?}

Dam operations have been experimentally modified through FEs to promote a larger or more diverse set of potential ecological and social benefits from river systems than have typically been achieved by traditional operations (Panel 1). In many cases, these desired benefits are not simple, direct consequences of releasing water from a dam but are contingent on other factors. Thus, experimental approaches have been advocated as a way to inform dam operation to achieve ecological and social objectives fairly and efficiently, given constraints associated with available water, infrastructure, and applicable laws.

Large-scale FEs are multidisciplinary in their scientific foci and management objectives. The primary motiva- tions for conducting such experiments include outcomes associated with natural resources (eg ecosystem of concern, protected area, subsistence resource), threatened and endangered species, regulatory or statutory requirements, and scientific understanding (Figure 3a). This suggests that iconic places and at-risk species (eg national parks, wildlife/fish) are important stimuli for initiating FEs. For example, Beervlei Dam (Groot River, South Africa) generally releases water at irregular intervals solely for irrigating agricultural lands, but an opportunity to conduct an FE arose when heavy rains filled its reservoir (Cambray 1991). The hypothesis underpinning this FE was whether flushing flows could decrease the salinity of pool habitats to initiate spawning of the globally endangered smallscale redfin minnow (Pseudobarbus asper). In another example, the federal designation of the endemic cui-ui sucker (Chasmistes cujus) as endangered prompted a flow restoration program on the heavily dammed Truckee River (US). Experimental releases of high spring flows were successful in promoting sucker reproduction and resulted in an unanticipated benefit of initiating extensive seedling recruitment of native Fremont cottonwood (Populus fremontii) and sandbar willow (Salix exigua) in the riparian floodplain (Rood et al. 2005).

Dam operation has benefited from FEs in terms of both 
learning and outcomes. When clear objectives were articulated prior to conducting FEs (ie objectives that included an explicit statement of expectations and/or hypotheses), experiments were twice as likely to achieve their stated objectives as compared to FEs without clearly articulated objectives (odds ratio $=2.2$, confidence interval $[\mathrm{CI}]=0.7-6.7$; Figure $3 \mathrm{~b}$ ). This finding has implications for the many FEs that are rapidly designed and conducted in response to fortuitous heavy precipitation events or dam repair requirements. Objectives that consider longer term dam management issues are not always formulated for these opportunistic experiments, and measureable outcomes are often evaluated retrospectively. We therefore recommend that regional collaborative (web-based) networks be assembled to develop contingency plans that allow for managers and scientists to respond rapidly to FE opportunities.

Effective large-scale FEs were also found to depend on a broader context that includes water managers and stakeholders who can use the results in decision making. Dam management practices were three times as likely to be modified when the management objectives of FEs were considered "achieved" versus "not met" (odds ratio $=3.1$, $\mathrm{CI}=1.2-8.2$; Figure 3c). Moreover, FEs intended solely for scientific purposes (ie excluding management outcomes) need only generate information to be considered "successful" but may have little impact on decision making. Indeed, FEs that failed to change dam management practices (and where management objectives were considered achieved) were approximately three times as likely to have involved experiments where scientific knowledge was the primary motivation (odds ratio $=2.8$, $\mathrm{CI}=0.8-10.6)$.
In summary, we found strong evidence that explicit articulation of management objectives during FE design, although not universally practiced in the past, is crucial for achieving favorable management outcomes and informing changes in dam management policies. Although meeting management objectives depends on diverse outcomes that cannot be achieved solely through single-event-based experiments, it is encouraging that past large-scale FEs are associated with identifiable changes in dam management practices. Clearly, such changes are rarely achieved when FEs are conducted solely to advance scientific knowledge without considering how that knowledge will inform dam operations, a trend shared broadly with adaptive management practices (Westgate et al. 2013).

\section{Are large-scale FEs advancing our scientific understanding and ability to inform future management and policy?}

Despite the widely reported importance of the flow regime (ie magnitude, frequency, seasonal timing, duration, and rate of change of flow) for river ecosystems (Poff et al. 1997; Bunn and Arthington 2002), large-scale FEs have only investigated the effects of a small range of discrete flow events. This is likely a consequence of the logistical and funding constraints to performing longterm environmental research (Konrad et al. 2011) and concerns from stakeholders with water use interests. To date, the majority of FEs tested the treatment effects of high pulse events and magnitude of minimum flows $(56 \%$ of experiments), whereas experiments involving seasonal variability $(9 \%)$ and flow regimes $(8 \%)$ were much less

\section{Panel 1. Ecological and societal benefits of large-scale flow experiments in freshwater ecosystems}

Water managers use flow experiments (FEs) for specific ecological or social outcomes, and many have been successful in achieving their management objectives according to evaluations over both short- and long-term timescales. Examples of the ecological and societal benefits of FEs in freshwater ecosystems are provided below.

Improved water quality, restoration of physical habitats and native biodiversity

- Increased flows have been used to reduce salinity in the Campaspe River, Australia (State Government of Victoria 20I0).

- Flushing flows released from Opuha Dam reduced filamentous green algae cover in the Opuha-Opihi River system, New Zealand (Arscott et al. 2007).

- High-flow pulses in the Bill Williams River, US, flushed beaver dams that were creating standing water conditions supporting nonnative fishes and helped regenerate native willow/cottonwood trees on floodplains (Shafroth et al. 2010).

- Delivery of minimum flows below Rocklands Dam in the Glenelg River, Australia, sustained the taxonomic composition of the macroinvertebrate assemblage during drought (Lind et al. 2007).

- Large winter release from Sejnane Dam in the Ichkeul River, Tunisia, increased emergent wetland vegetation and nesting habitat for waterfowl (Smart 2004).

Increased economic value from natural resources

- Seasonal releases to inundate floodplain wetlands increased fisheries, agricultural, and livestock production in the River Senegal, Mauritania (Duvail and Hamerlynck 2003), and Logone River, Cameroon (Scholte et al. 2000).

- Flows targeting migration, spawning, and rearing life stages of Pacific salmon have increased survival and reproduction of populations in the Columbia River, US (Williams et al. 2005), and Gudbrandsdalslågen River, Norway (Kraabol et al. 2008).

- High-flow pulses following closure of Glen Canyon Dam scoured finer sediment from the tailwater of the Colorado River, US, transforming the former sand-bed channel to a gravel bed (Schmidt et al. 200I), improving habitat conditions that allowed establishment of a recreational trout fishery; later, re-operation of the dam to reduce hydro-peaking also allowed natural trout reproduction to occur, ending the need to stock the fishery (Korman et al. 2012). 
common (Figure 4a). The relative paucity of FEs involving flow variability conflicts with their overwhelming ecological importance (Naiman et al. 2008) and their role in emerging sustainable river management practices, laws, and regulations (Poff 2009; Richter et al. 2012). About $80 \%$ of investigated experiments focused only on discrete flow events, thereby limiting their potential to inform dam management and environmental flow policy. The time frames of FEs also vary considerably, ranging from tests of discrete flow events (eg King et al. 1998; Schmidt et al. 2001; Shafroth et al. 2010) to longer term monitoring policies (eg Bradford et al. 2011; Melis et al. 2012; Robinson 2012). Reconciling the knowledge gained from investigations of discrete manipulations with the need to inform longer term policies is critical for improving dam re-operation and environmental flow schemes.

Large-scale FEs have investigated a variety of abiotic outcomes (Figure 4b). Although quantifying multiple abiotic outcomes, which equally span conditions of water quality, hydrology, and geomorphology, most FEs examined only a single biological variable, with a dominant focus on freshwater fishes (Figure 4c). Perhaps this outcome is to be expected, given that simple operational rules still dominate water resource management (Jager and Smith 2008) and that these rules were typically developed at individual facilities under federal mandates (eg the US Endangered Species Act) or to promote recreational fisheries (Figure 3a). Moreover, outcomes measured in terms of socially valued resources (ie fish) are often the principal motivation for water managers to manipulate flows and may be the only acceptable justification of the costs and risks of such actions (Konrad et al. 2011). However, the fact that only one-third of experiments examined multiple taxonomic groups is troubling, given the shift from a simple "one size fits all" reservoir operations rule to a more flexible prescription of environmental flows to meet the needs of multiple ecosystem components (Poff 2009). Notably, very few FEs evaluated the responses of ecosystem processes (such as rates of metabolism, nutrient cycling, fluxes of nutrients and energy) or community trophic structure and food web dynamics, all of which can be strongly influenced by hydrologic variation (but see Watts et al. [2010] and Cross et al. [2011]). It is encouraging that almost $80 \%$ of FEs recorded both abiotic and biotic outcomes, thereby enhancing our understanding of the mechanisms of ecological responses to flow manipulation. But the potential for greater gains in knowledge necessitates improving FE efficiency and value. This is illustrated by the larger number of FEs resulting in changed dam management practices when both abiotic and biotic outcomes were quanti- fied as compared to when only one response type was examined (odds ratio $=1.6, \mathrm{CI}=0.5-4.9$ ).

Realizing the ecological and societal benefits of FEs requires dedicated long-term resources, including funding and personnel. Decreased monitoring and evaluation over time may appear fiscally responsible, but reduced surveillance may eventually impede the detection of longer term ecological responses and informed decision making and policy (Poff et al. 2003; Konrad et al. 2011). The variability of post-FE activity duration is striking. Short-term commitments that involved repeated postexperiment sampling for less than a year were relatively common ( $72 \%$ of experiments), whereas longer term commitments, such as the establishment of monitoring programs for at least a year after the FE and the occurrence of additional FEs (subsequent to the focal FE), took place in only $60 \%$ and $32 \%$ of the instances, respectively (Figure 4d). Although evaluating FE success over short timescales is important (Richter et al. 2003), in many cases an experimental design may require years before any effects are demonstrated (Souchon et al. 2008); the time period is likely scaled to rates of physiochemical processes and to target species' life histories (Beechie et al. 2010). For instance, invertebrate community structure in the River Spöl (Switzerland) only shifted after years of repeated high-flow pulses (Robinson 2012). Similarly, multi-year monitoring was needed to reveal FE-induced changes in salmonid production in Bridge Creek 
(a) Treatment type

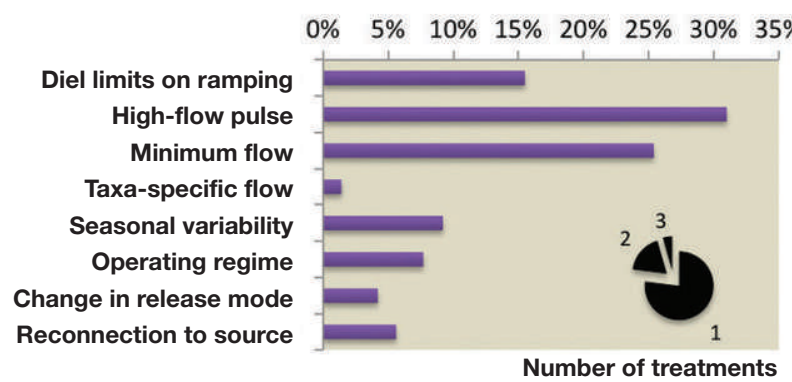

(b) Abiotic outcomes

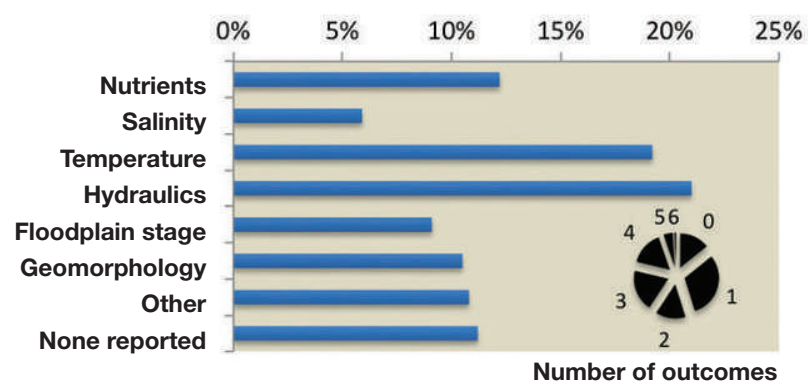

(c) Biotic outcomes

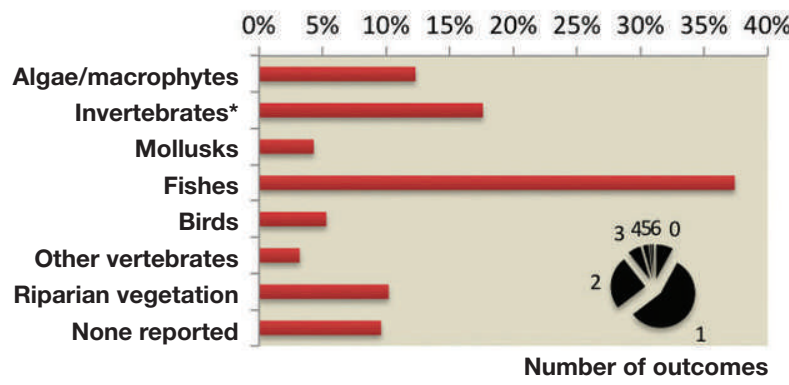

(d) Post-FE activities

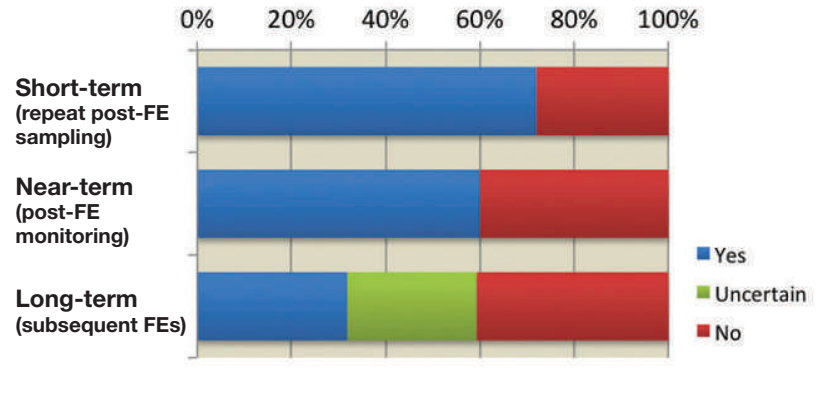

Figure 4. (a) Large-scale FEs have involved a variety of treatments, evaluating a wide range of (b) abiotic and (c) biotic outcomes and including $(d)$ post-FE activities operating over different timescales. Inset pie graphs report the relative proportion of experiments (wedge size) examining different numbers of treatments or outcomes. *Exclusive of mollusks. Descriptor details are in WebPanel 1.

(Canada) (Bradford et al. 2011), and Rood et al. (2005) described the sequence of flows over a period of years necessary to establish cottonwoods on the Truckee River (US). Interestingly, management objectives were more than four times as likely to be achieved when ongoing experimentation of flow regimes occurred (odds ratio $=$ $4.4, \mathrm{CI}=1.7-11.0$ ), demonstrating the critical need for continued investment in FEs in combination with regular assessment of monitoring data and modeling (King et al. 2010; Korman et al. 2012).

\section{What are the major challenges and emerging opportunities for future FEs?}

In an uncertain future, characterized by human population pressure and global climate change, dams will play an important role in meeting commitments such as the Millennium Development Goals to address energy and water poverty (Naiman and Dudgeon 2011; McDonald et al. 2012). Commitments to reduce greenhouse-gas emissions under the Kyoto Protocol provide new incentives for developing hydropower dams, whereas the mandatory relicensing of aging dams offers opportunities to renovate water-release structures and reassess operations (Pittock and Hartmann 2011). How then can dams be designed and operated so that the benefits outweigh the social and environmental costs? This cannot be answered simply through a planning process either before or after dam construction. Anticipating the full range of positive and negative consequences of dam building is complicated by substantial uncertainties about ecosystem responses. Furthermore, because societal values underlying these benefits and costs change over time, the question of trade-offs must be revisited periodically. Sustainable and equitable water resource development depends on effective adaptive management, with dams capable of releasing water in ways that mimic natural flow variability. The adoption of FEs is an integral part of informing desired release operations.

Large-scale experiments offer a practical approach to inform water policies and decisions, but they also require substantial commitment by scientists, managers, and stakeholders. Can we expect such experiments to be funded and implemented without critically evaluating ongoing and past projects? What evidence is there that FEs are providing relevant information? In an increasingly resource-limited society, how does the science of FEs remain credible and can it distinguish effective from ineffective management? In an effort to address these questions, our systematic review highlights challenges and opportunities for future FE implementation.

Practitioners of future FEs will be challenged to develop coordinated treatments and common response measures that enhance information transfer across multiple projects, while still recognizing the importance of case-specific context. Even with similar experimental designs, however, treatment strength, stressors other than flow, and the choice of ecological targets all influence the efficacy of flow manipulations to achieve specific outcomes. For example, water temperature is often measured but 
rarely manipulated during large-scale FEs, despite the ecological importance of thermal regimes and the impact of dams on this parameter (Olden and Naiman 2010). The inability to simultaneously manipulate both flow and temperature during FEs has repeatedly been cited as an obstacle to achieving management goals (eg Bradford et al. 2011; Melis et al. 2012). FEs that quantify the effects of specific dam operations (eg flow versus temperature) will undoubtedly advance our mechanistic knowledge but may necessitate experiments at inconvenient times or the postponement of some management actions while others are evaluated. Furthermore, monitoring efforts should be accompanied by assessment of social responses to ecosystem change in order to identify stakeholder satisfaction with experimental outcomes. Stakeholders will value ecological outcomes in the form of goods and services they wish to sustain or improve, so their reactions to altered provision of ecosystem goods and services will provide another indicator of success (Arthington 2012).

Obtaining funding and institutional support for largescale FEs will be crucial (Poff et al. 2003), yet the economic value of implementing dam operational changes to promote key ecosystem goods and services has rarely been considered. Although it is premature to expect that the economic benefits of experimental releases will completely justify their costs, FEs could facilitate documentation and valuation of ecological outcomes that support important ecosystem goods and services (Wilson and Carpenter 1999). Deriving such estimates will be challenging but not impossible, given the continued difficulty of placing monetary values on ecosystem services (Daily et al. 2009). With increasing market value of environmentally sound electricity production in some regions, we also expect to see potential intangible benefits associated with enhancing the environmental image of dam operators who embrace FEs. For example, the Engadin Hydroelectric Power Company recently certified its production in the River Spöl - a system that has experienced numerous FEs since 2000 (Robinson 2012) - as environmentally sound through the Swiss label "naturemade basic". In summary, FEs that provide information on economic benefits would enhance their relevancy to stakeholders (Poff et al. 2003) and could inform the operations of experimental releases (Duvail and Hamerlynck 2003).

Large-scale FEs provide unparalleled opportunities for interdisciplinary investigation of the full range of ecosystem goods and services affected by reservoir management and for informing scientifically based operating strategies that serve both ecological sustainability and social equity. Such knowledge will become increasingly important as reservoir management strategies, typically guided by only a few principal objectives, are re-examined to achieve multiple ecological and societal outcomes. Unfortunately, our findings suggest that past large-scale FEs have rarely capitalized on these opportunities. Moreover, although the number of FEs has increased in recent decades, the publication of findings in the peer-reviewed literature remains limited, and until now there was no open-access data archive of key metrics and results from these experiments to inform an evidence-based framework for future efforts (the complete $\mathrm{FE}$ database is available at http://dx.doi.org/10.6084/m9.figshare.761221).

In conclusion, we argue for enhancing collaboration between scientists, managers, and policy makers involved in FEs to support sustainable freshwater management. There is a clear need to diversify the geographical, sociopolitical, and ecological context in which future FEs are conducted, and such efforts must not be limited to pursuing scientific discovery at the cost of managerial and policy relevance (Keith et al. 2011). Scientists should strive to develop FEs in the spirit of adaptive management that inform river management and advance scientific knowledge (Konrad et al. 2011) and refrain from using policy demands to pursue discovery goals not relevant to decision making. At the same time, managers and policy makers must embrace both the scientific uncertainty and surprise learning opportunities that inevitably arise from these experiments, and not purposely ignore uncertainty to avoid complicating their message to stakeholders, only to later invoke this issue when FEs fail to deliver expected ecological or social outcomes. By working together to embrace new thinking and effectively utilize the wealth of knowledge garnered from past experiments, we envision that future FEs will represent a critical part of strategic adaptive management efforts seeking to credibly guide water policies and decisions across the globe.

\section{Acknowledgements}

We thank D Carlisle for his comments on the manuscript. This contribution is based on the workshop "Evaluating Responses of Freshwater Ecosystems to Experimental Water Management", funded by the National Center for Ecological Analysis and Synthesis (NCEAS Project 12374).

\section{References}

Acreman MC, Farquharson F, McCartney MP, et al. 2000. Managed flood releases from reservoirs: issues and guidance. Wallingford, UK: Centre for Ecology and Hydrology, Department for International Development, and World Commission on Dams.

Arscott DB, Kelly DJ, and Tuck E. 2007. Flushing flows for the control of nuisance periphyton growth in the Opuha-Opihi River system (2004-2006). Christchurch, New Zealand: National Institute of Water and Atmospheric Research Ltd.

Arthington AH. 2012. Environmental flows: saving rivers in the third millennium. Berkeley, CA: University of California Press.

Bednarek AT and Hart DD. 2005. Modifying dam operations to restore rivers: ecological responses to Tennessee River dam mitigation. Ecol Appl 15: 997-1008.

Beechie TJ, Sear DA, Olden JD, et al. 2010. Process-based principles for restoring river ecosystems. BioScience 60: 209-22.

Bradford MJ, Higgins PS, Korman J, et al. 2011. Test of an environmental flow release in a British Columbia river: does more water mean more fish? Freshwater Biol 56: 2119-34.

Bunn SE and Arthington AH. 2002. Basic principles and ecologi- 
cal consequences of altered flow regimes for aquatic biodiversity. Environ Manage 30: 492-507.

Cambray JA. 1991. The effects on fish spawning and management implications of impoundment water releases in an intermittent South African river. Regul River 6: 39-52.

Cook T. 2013. A flood of controversy on the Colorado River. Earth March: 40-46.

Cross WF, Baxter CV, Donner KC, et al. 2011. Ecosystem ecology meets adaptive management: food web response to a controlled flood on the Colorado River, Glen Canyon. Ecol Appl 21: 2016-33.

Daily GC, Polasky S, Goldstein J, et al. 2009. Ecosystem services in decision making: time to deliver. Front Ecol Environ 7: 21-28.

Duvail S and Hamerlynck O. 2003. Mitigation of negative ecological and socio-economic impacts of the Diama Dam on the Senegal River Delta wetland (Mauritania), using a model based decision support system. Hydro Earth Sys Sci 7: 133-46.

Finer M and Jenkins CN. 2012. Proliferation of hydroelectric dams in the Andean Amazon and implications for Andes-Amazon connectivity. PLoS ONE 7: e35126.

Gleick PH. 2003. Water use. Annu Rev Env Resour 28: 275-314.

Haeuber RA and Michener WK. 1998. Policy implications of recent natural and managed floods. BioScience 48: 765-72.

Jager HI and Smith BT. 2008. Sustainable reservoir operation: can we generate hydropower and preserve ecosystem values? River Res Appl 24: 340-52.

Keith DA, Martin TG, McDonald-Madden E, et al. 2011. Uncertainty and adaptive management for biodiversity conservation. Biol Conserv 144: 1175-78.

Kiernan JD, Moyle PB, and Crain PK. 2012. Restoring native fish assemblages to a regulated California stream using the natural flow regime concept. Ecol Appl 22: 1472-82.

King AJ, Ward KA, O'Connor P, and Green D. 2010. Adaptive management of an environmental watering event to enhance native fish spawning and recruitment. Freshwater Biol 55: 17-31.

King JM, Cambray JA, and Impson ND. 1998. Linked effects of dam-released floods and water temperature on spawning of the Clanwilliam yellowfish Barbus capensis. Hydrobiologia 384: 245-65.

Kingsford RT, Biggs HC, and Pollard SR. 2011. Strategic adaptive management in freshwater protected areas and their rivers. Biol Conserv 144: 1194-203.

Konrad CP, Olden JD, Lytle DA, et al. 2011. Large-scale flow experiments for managing river systems. BioScience 61: 948-59.

Konrad CP, Warner A, and Higgins JV. 2012. Evaluating dam reoperation for freshwater conservation in the sustainable rivers project. River Res Appl 28: 777-92.

Korman J, Martell SJD, Walters CJ, et al. 2012. Estimating recruitment dynamics and movement of rainbow trout in the Colorado River in Grand Canyon using an integrated assessment model. Can J Fish Aquat Sci 69: 1-23.

Kraabol M, Arnekleiv JV, and Museth J. 2008. Emigration patterns among trout, Salmo trutta (L), kelts and smolts through spillways in a hydroelectric dam. Fish Manage Ecol 15: 417-23.

Lehner B, Liermann CR, Revenga C, et al. 2011. High-resolution mapping of the world's reservoirs and dams for sustainable river-flow management. Front Ecol Environ 9: 494-502.

Lind PR, Robson BJ, and Mitchell BD. 2007. Multiple lines of evidence for the beneficial effects of environmental flows in two lowland rivers in Victoria, Australia. River Res Appl 23: 933-46.

McDonald RI, Olden JD, Opperman JJ, et al. 2012. Energy, water and fish: biodiversity impacts of energy-sector water demand in the United States depend on efficiency and policy measures. PLoS ONE 7: e50219.

McMullen LE and Lytle DA. 2012. Quantifying invertebrate resistance to floods: a global-scale meta-analysis. Ecol Appl 22: 2164-175.
Melis TS, Korman J, and Kennedy TA. 2012. Abiotic and biotic responses of the Colorado River to controlled floods at Glen Canyon Dam, Arizona, USA. River Res Appl 28: 764-76.

Moore M, Romano SP, and Cook T. 2010. Synthesis of upper Mississippi River system submersed and emergent aquatic vegetation: past, present, and future. Hydrobiologia 640: 103-14.

Naiman RJ and Dudgeon D. 2011. Global alteration of freshwaters: influences on human and environmental well-being. Ecol Res 26: 865-73.

Naiman RJ, Latterell JJ, Pettit NE, et al. 2008. Flow variability and the biophysical vitality of river systems. CR Geosci 340: 629-43.

Olden JD and Naiman RJ. 2010. Incorporating thermal regimes into environmental flows assessments: modifying dam operations to restore freshwater ecosystem integrity. Freshwater Biol 55: 86-107.

Palmer MA, Liermann CAR, Nilsson C, et al. 2008. Climate change and the world's river basins: anticipating management options. Front Ecol Environ 6: 81-89.

Patterson RJ and Smokorowski KE. 2011. Assessing the benefit of flow constraints on the drifting invertebrate community of a regulated river. River Res Appl 27: 99-112.

Pittock J and Hartmann J. 2011. Taking a second look: climate change, periodic relicensing and improved management of dams. Mar Freshwater Res 62: 312-20.

Poff NL. 2009. Managing for variability to sustain freshwater ecosystems. J Water Res Plan Manage 135: 1-4.

Poff NL, Allan JD, Bain MB, et al. 1997. The natural flow regime. BioScience 47: 769-84.

Poff NL, Allan JD, Palmer MA, et al. 2003. River flows and water wars: emerging science for environmental decision making. Front Ecol Environ 1: 298-306.

Pullin AS and Stewart GB. 2006. Guidelines for systematic review in conservation and environmental management. Conserv Biol 20: $1647-56$.

Ralston BE. 2011. Summary report of responses of key resources to the 2000 Low Steady Summer Flow Experiment, along the Colorado River downstream from Glen Canyon Dam, Arizona. Reston, VA: US Geological Survey. USGS Open-File Report 2011-1220.

Richter BD and Thomas GA. 2007. Restoring environmental flows by modifying dam operations. Ecol Soc 12: 12 .

Richter BD, Mathews R, and Wigington R. 2003. Ecologically sustainable water management: managing river flows for ecological integrity. Ecol Appl 13: 206-24.

Richter BD, Davis MM, Apse C, et al. 2012. A presumptive standard for environmental flow protection. River Res Appl 28: 1312-21.

Robinson CT. 2012. Long-term changes in community assembly, resistance, and resilience following experimental floods. Ecol Appl 22: 1949-61.

Rood SB, Samuelson GM, Braatne JH, et al. 2005. Managing river flows to restore floodplain forests. Front Ecol Environ 3: 193-201.

Schmidt JC, Parnell RA, Grams PE, et al. 2001. The 1996 controlled flood in Grand Canyon: flow, sediment transport, and geomorphic change. Ecol Appl 11: 657-71.

Schmidt JC, Webb RH, Valdez RA, et al. 1998. Science and values in river restoration in the Grand Canyon. BioScience 48: $735-47$.

Scholte P, Kirda P, Adam S, and Kadiri B. 2000. Floodplain rehabilitation in north Cameroon: impact on vegetation dynamics. Appl Veg Sci 3: 33-42.

Shafroth PB, Wilcox AC, Lytle DA, et al. 2010. Ecosystem effects of environmental flows: modelling and experimental floods in a dryland river. Freshwater Biol 55: 68-85.

Smart M. 2004. River flow regulation and wetland conservation in a dry country: Ichkeul, Tunisia. In: Assessment and provision of 
environmental flows in Mediterranean watercourses. Malaga, Spain: IUCN Centre for Mediterranean Cooperation.

Souchon Y, Sabaton C, Deibel R, et al. 2008. Detecting biological responses to flow management: missed opportunities, future directions. River Res Appl 24: 506-18.

State Government of Victoria. 2010. Environmental watering in Victoria 2009/10. Melbourne, Australia: Victorian Government.

Watts RJ, Richter BD, Opperman J, et al. 2011. Dam reoperation in an era of climate change. Mar Freshwater Res 62: 321-27.

Watts RJ, Ryder DS, Allan C, et al. 2010. Using river-scale experiments to inform the adaptive management process for variable flow releases from large dams. Mar Freshwater Res 61: 786-97.

Westgate MJ, Likens GE, and Lindenmayer DB. 2013. Adaptive management of biological systems: a review. Biol Conserv 158: 128-39.

Wilcock PR, Barta AF, Shea CC, et al. 1996. Observations of flow and sediment entrainment on a large gravel-bed river. Water Resour Res 32: 2897-909.
Williams JG, Smith SG, Zabel RW, et al. 2005. Effects of the federal Columbia River power system on salmonid populations. Seattle, WA: Northwest Fisheries Science Center. Report NMFS-NWFSC-63.

Wilson MA and Carpenter SR. 1999. Economic valuation of freshwater ecosystem services in the United States. Ecol Appl 9: $772-83$.

${ }^{6}$ Donald Bren School of Environmental Science and Management, University of California, Santa Barbara, Santa Barbara, CA; ${ }^{7}$ Division of Biology, Kansas State University, Manhattan, KS; ${ }^{8}$ Sequoia National Forest, US Forest Service, Porterville, CA; ${ }^{9}$ Department of Zoology, Oregon State University, Corvallis, OR; ${ }^{10}$ ICF International, Portland, OR; ${ }^{11}$ Department of Biology, Ball State University, Muncie, IN; ${ }^{12}$ Swiss Federal Institute of Aquatic Science and Technology, Dübendorf, Switzerland; ${ }^{13}$ Department of Watershed Sciences, Utah State University, Logan, UT

\section{Climate Change and U.S. Natural Resources: Advancing the Nation's Capability to Adapt}

This Issue provides a broad perspective on approaches for adapting to climate-change impacts on national water and land resources as well as biodiversity. Using examples from different settings, it explores applications of management options that allow natural and managed systems to adjust to the range of potential variations in future climate conditions.

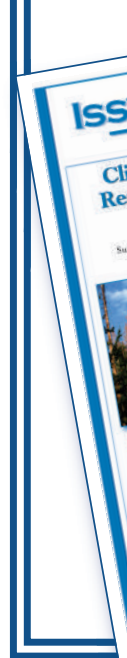

\section{ESA's Issues in Ecology series}

- reports a consensus of a panel of scientific experts

- uses clear, commonly understood language

- focuses on issues related to the environment

- is intended for scientists, educators, students, and decision makers

- is reviewed by external experts for technical content

\section{Copies are available in print (order online) and as a PDF (free download)}

For more information, visit: www.esa.org/issues 